\title{
Tumor-Specific Systemic Treatment in Advanced Breast Cancer - How Long does it Make Sense?
}

\author{
Rachel Wuerstlein Ingo Bauerfeind \\ Brustzentrum, Universitäts-Frauenklinik, Universitätsklinikum Köln, Germany
}

\section{Keywords}

Metastatic breast cancer - Terminal illness .

Palliative care $\cdot$ Communication $\cdot$ Patient-centered care

\section{Summary}

Metastatic breast cancer ( $\mathrm{MBC}$ ) is a chronic and incurable disease which can be kept steady for a long time with continuous oncologic therapy. There are various treatment options. Disease-free as well as overall survival were prolonged in many pharmaceutical studies. The therapist focuses on these oncologic parameters as well as the patient's quality of life. One central point of the communication between doctor and patient is the prediction by the medical team of how long to continue oncologic therapy and when to start palliative medicine in terms of best palliative care. Treatment options currently available for $\mathrm{MBC}$ as well as the importance of this difficult communication between the involved parties are pointed out. The end of tumor-specific oncologic therapy does not necessarily mean the end of therapeutic measures for the individual patient.

\section{Introduction}

In daily work, two challenging situations occur with patients with metastatic breast cancer (MBC), which are at the center of this overview: i) A patient with widespread metastatic disease dies 'surprisingly' after an intravenous chemotherapy given $24 \mathrm{~h}$ prior to death. The attitude of all involved parties (family, caregivers, physicians) can be best described by the

\author{
Schlüsselwörter \\ Metastasiertes Mammakarzinom - Endstadium . \\ Palliativmedizinische Versorgung - Kommunikation . \\ Patientenzentrierte Versorgung
}

\section{Zusammenfassung}

Das metastasierte Mammakarzinom ist eine chronische und unheilbare Erkrankung, die unter fortdauernder onkologischer Therapie lange stabil gehalten werden kann. Die Therapieentscheidungsmöglichkeiten sind vielfältig. Zahlreiche Medikamentenstudien konnten das krankheitsfreie Überleben und auch das Gesamtüberleben verlängern. Neben diesen onkologischen Parametern steht jedoch auch die Lebensqualität der Patientin im Mittelpunkt therapeutischer Bemühungen. Die Prognoseabschätzung der behandelnden Ärzte und der Betreuungsteams bleibt ein Kernpunkt der Arzt-Patienten-Gespräche bei der Entscheidung zur Fortsetzung onkologischer Systemtherapien oder der Einleitung palliativmedizinischer symptomorientierter Therapien im Sinne von Best Palliative Care. Neben den heute zur Verfügung stehenden Behandlungsoptionen beim MBC wird die Bedeutung dieser schwierigen Kommunikationssituation für die Beteiligten aufgezeigt. Das Ende der tumorspezifischen onkologischen Therapie bedeutet nicht das Beenden therapeutischer Maßnahmen für die individuelle Patientin.

words: 'At least, everything was tried.'; ii) A patient dies after the decision was made to stop treatment and start best palliative care. In many situations someone of the involved parties will say: 'Did we really try everything?'. The decision whether to continue or discontinue systemic treatment in MBC and offer palliative care is essential and will be discussed in more detail later. This issue is beyond a question that can be addressed in a prospective randomized trial.

\section{KARGER \\ Fax +497614520714 \\ Information@Karger.de}

www.karger.com (c) 2011 S. Karger GmbH, Freiburg

$1661-3791 / 11 / 0061-0035 \$ 38.00 / 0$

Accessible online at:

www.karger.com/brc
Dr. med. Rachel Würstlein

Universitäts-Frauenklinik, Brustzentrum

Universitätsklinikum Köln (AöR)

Kerpener Str. 34, 50931 Köln, Germany

Tel. +49 221 478-87743, Fax -97440

rachel.wuerstlein@uk-koeln.de 
Despite long years of research, $\mathrm{MBC}$ remains incurable, and the median survival time is about 2-3 years after first documentation of metastasis. On the other hand, chronic MBC patients have been treated for many years, some of them to the 7 th or 8 th line of treatment. Approximately $10 \%$ of newly diagnosed breast cancer patients have locally advanced breast cancer and or $\mathrm{MBC}$, and $20-85 \%$ in an adjuvant early setting will develop recurrent and or metastatic disease depending on the initial stage, tumor biology, treatment strategy, and diagnostic sensitivity [1]. Most frequently, metastases can be found in bone, lung/pleura, liver, brain, locoregionally, and intraabdominally, but all other organs can be affected. If a disease is incurable, like MBC, treatment should focus on optimal anticancer treatment aimed at prolonging overall survival (OS) and disease-free survival (DFS) and preserving quality of life, as well as providing symptom management and best supportive care including open and honest communication with the patients and their families.

During the last 30 years, OS in patients with breast cancer has improved [2], with median survival of patients with MBC ranging from 20 to 28 months, mainly depending on location of metastasis and tumor biology [3, 4]. In a recently presented overview regarding OS and post-progression survival (PPS) in advanced breast cancer, a gain in OS was reported in only $19.7 \%$ of 76 trials (median gain 4.7 months) [5]. Improved OS was more frequent when there was significant gain in progression-free survival (PFS). The average median OS was 20.7 months in trials assessing first-line chemotherapy and 31.1 months in trials with first-line hormone therapy. PPS represents two thirds of patient survival after the trial. Gueth et al. [6] reported the following data for an unselected patient group comparing the intervals from 1990 to 1997 and from 1998 to 2006: median metastatic disease-specific survival increasing from 16 to 21 months with a surprisingly high number of patients with no treatment in MBC $(10 \% ;>70$ years: $19.3 \%$ ). Only $26 \%$ received more than three chemotherapy lines, and the 3 -year survival rate was 38.5 vs. $23.8 \%$, and 5 -year survival 16.6 vs. $12.6 \%$.

Little data exists on prolonging OS $[1,5]$. For years, OS was considered to be the most important therapeutic objective in MBC. However, OS is also influenced by therapies used after participation in a given trial, the fast implementation of promising new substances, alternative medications not reported to the doctors, or the setting. Because a lot of trials are underpowered to show OS differences, PFS and time to progression (TTP) have been introduced in the course of trials in MBC as primary endpoints. Prolonged PFS and TTP however do not always translate into better overall survival. PFS and TTP are available earlier and independent of postprogression treatment and crossover. The majority of trials use response rate (RR), PFS, and TTP (typical surrogate parameters) as primary endpoints, taking into account the limitation of response assessment as an indicator of treatment benefit in oncology and the missing link between treatment effects on response and survival $[5,7,8]$. Fortunately, data have become more comparable by the efficacy of a systemic treatment, which can be staged by measuring a marker lesion following the RECIST criteria [9], making results comparable. But still, the different trial endpoints and crossovers make the comparison of clinical trial outcomes difficult.

\section{Treatment Considerations}

In contrast to well-defined national and international guidelines in adjuvant treatment, there is no strongly defined standard of care for patients with MBC, mainly after first-line treatment, and only a small percentage of patients are involved in clinical trials. The decision for systemic treatment should take into account the following factors influencing treatment options $[1,4,6]$ : i) Patient-related factors: (biological) age, comorbidities, physical condition, personal preference (substance, application, interval, side effect tolerance), and motivation; ii) Prognostic factors: interval from initial diagnosis to metastatic disease, previous response to systemic treatment, rate of disease progression, number and location of metastases. iii) Biological factors: hormone receptor, HER2/neu; iv) Case-related factors: adjuvant and palliative pretreatment, option of surgical/radiology-guided excision of metastases; v) Symptom-related factors: need for fast intervention (vital involvement of visceral organs or brain), symptom burden; vi) Therapy-related factors: expected efficacy, type and extent of side effects/toxicity, complications during prior treatment; vii) Physician-related factors: estimation of prognosis, experience, setting, personal preference of agents, motivation of the patient, skills in supportive care/management of side effects; viii) Socioeconomic factors: social status, availability of agents.

Treatment in MBC must strictly balance the benefits of treatment and the possible side effects and therefore introduce as early as possible supportive treatment to maximize control of symptoms, prevent serious complications, and prolong survival while maintaining quality of life. Therefore, the adverse effects of any treatment need to be predictable, manageable, and reversible. Some paradigms in the treatment of MBC have changed: i) Excision of the primary breast tumor in $\mathrm{MBC}$ for tumor reduction, which has been retrospectively proven to improve DFS and OS [10]; and ii) Combination and prolongation of biological treatments such as trastuzumab beyond progression [11]. It is evident that outcome varies depending on tumor factors and host factors [12].

For some other solid tumors, the effects of palliative care have been found to be effective even on OS [13]. Palliative care is not the systemic treatment of metastatic disease, but means best supportive care treatment in the end-of-life care, which needs early integration in the therapeutic setting. Palliative care is defined as improvement of quality of life of patients and their families facing the problems associated with 
life-threatening illness, through the prevention and relief of suffering by means of pain and other problems, physical, psychosocial, and spiritual (WHO definition of palliative care, $w w w . w h o . i n t)$. Palliative care provides relief from pain and other distressing symptoms; affirms life and regards dying as a normal process; intends to neither hasten nor postpone death; integrates the psychosocial and spiritual aspects of patient care; offers a support system to help patients live as actively as possible until death; offers a support system to help the family cope during the patients illness and in their own bereavement; uses a team approach to address the needs of patients and their families, including bereavement counseling, if indicated; will enhance quality of life, and may also positively influence the course of illness; is applicable early in the course of illness, in conjunction with other therapies that are intended to prolong life, such as chemotherapy or radiation therapy, and includes those investigations needed to better understand and manage distressing clinical complications.

Data on the patients' view of health-related quality of life is rare. Nowadays, patients (and families) should know about the prognosis of MBC and the effects of modern treatment options. Many patients still would choose chemotherapy for a small benefit in health outcome [14] and willing undergo treatments that have small benefits with major toxicity sometimes without being given realistic information about the different options of care and the effect on life quality. Patientshared decision making remains difficult in palliative care [15]. Shared decision making has an impact on patient anxiety, recall of information, and satisfaction $[16,17]$ with the consultation and the emotional support given. Encouraging this participation should be the standard approach to patientdoctor communication.

To find the optimal management of MBC and the optimal timing for deciding on best supportive care remains a significant therapeutic challenge. Protocols for delivering bad news have been developed, such as the SPIKES protocol consisting of 6 steps to facilitate this complex communication task and prevent miscommunication. SPIKES means: Setting up the interview, assessing the patients perception, obtaining the patients invitation, giving knowledge and information to the patient, addressing the patients emotions with empathic responses, and giving strategy and summary [18]. To structure the communication of important information and to ensure competence in end-of-life care for physicians, Gunten et al. [19] describe a 7-step approach for communication and relational skills: Physicians should prepare for discussions by confirming medical facts and establishing the appropriate environment; establish what the patient and family know by using open-ended questions; determine how information is to be handled at the beginning of the patient-physician relationship; deliver the information in a sensitive but straightforward manner; respond to emotions of the patients, parents, and families; establish goals for care and treatment priorities when possible; and establish an overall plan. This application is part of end-of-life care competence and helps to improve the patients' experience of care, to avoid conflicts, and to enhance physicians' satisfaction with their relationship to the patients and their families.

\section{Special Treatment Options in MBC}

A wider array of agents is available for the treatment of MBC. Since MBC is estimated to be a chronic disease, therapy should be given continuously until best response is obtained or tumor progression occurs, and therapy should be stopped in non-acceptable toxicity situations. The benefit of treatment beyond progression is proven for endocrine therapy as well as for HER2/neu targeted therapy, in respect to treatment toxicity and safety. In chemotherapy, the number of treatment cycles is unclear, and depends on (long-term) toxicity and patient choice. Despite years of research and clinical trials, no predictive factors for $\mathrm{MBC}$ are available for routine clinical use. This underlines the relevance of re-evaluation of predictive marker/tumor biology in the metastases by biopsy, including hormone receptors and HER2/neu [20-22]. All recommendations and guidelines can be found at www.ago-online.de.

\section{Hormone Receptor-Positive MBC}

National and international guidelines recommend the use of endocrine treatment as first-line therapy in patients with hormone-sensitive MBC. Aromatase inhibitors with a variety of steroidal and non-steroidal agents are recommended as first-line therapy in postmenopausal woman [23, 24], and tamoxifen and fulvestrant as a treatment option after failure of first-line endocrine therapy. In premenopausal woman, the first choice is tamoxifen and ovarian suppression or aromatase inhibitor plus ovarian suppression. In the case of failure of both substances, fulvestrant is used as further therapy [23, 25]. Endocrine therapy after chemotherapy as maintenance has shown better TTP and OS [23]. Endocrine therapy also can be used in combination with HER2/neu targeted therapies (trastuzumab or lapatinib) and is indicated in patients not selected for chemotherapy, with better RR and PFS [26, 27].

\section{HER2/neu-Positive MBC}

The addition of trastuzumab to chemotherapy in the first-line setting resulted in an improved TTP and OS [28, 29]. Benefits have been shown for different combination therapies with best OS in trastuzumab plus capecitabine [30]. Upon disease progression, there are two options: continuation of trastuzumab with another systemic treatment (extension of trastuzumab) [11] or switch to another targeted therapy. The additional use of lapatinib has proven beneficial [31] as well as the combination of trastuzumab and lapatinib [32]. Monoclonal antibodies alone or in combination, such as pertuzumab, are under investigation. Trastuzumab-DM1 is a novel HER2/neu 
antibody drug conjugating trastuzumab and maytansine as a highly potent drug for which phase II trials have demonstrated strong clinical benefit in heavily pretreated patients. As mechanisms of resistance are known, new substances are on their way to clinical trials.

\section{Chemotherapy}

Cytotoxic chemotherapy is the treatment option in patients with aggressive disease, symptomatic disease (e.g. pain or acute dyspnea), short DFS since the last treatment, hormone receptor- and/or HER2/neu-negative disease, refractory disease for endocrine options, or indication for combined antibody treatment. There is no predictive marker for the use of chemotherapy and no defined target [33], and very often patients are heavily pretreated.

The use of anthracyclines and taxanes as the most understood treatment option in MBC is very often limited due to its use in the adjuvant setting [8]. Agents such as capecitabine, vinorelbine, or combinations with gemcitabine or ixabepilone have demonstrated benefits. In triple-negative MBC, little data is available on platinum-based regimens [23] and upcoming data on the use of PARP inhibitors. Novel agents such as nanoparticle albumin-bound paclitaxel, epothilones, or substances such as vinflunine, eribulin and trabectedin are being developed.

Examining the literature on combination chemotherapy versus single-agent chemotherapy in $\mathrm{MBC}$, there is little data favoring the combination with respect to OS [1, 5, 33-35]. Therefore, single-agent therapy should be preferred in the absence of rapid clinical progress, life-threatening metastases, or a need for rapid symptom control. There is evidence for the use of weekly regimens in comparison to 3-weekly treatments [36] as well as a trend towards the development of new application forms. In some patients, weekly chemotherapy can be given as well as endocrine treatment as long as no progression occurs and side effects are manageable. So far, best survival rates have been reported for combination chemotherapy and biological agents compared to chemotherapy alone or in combination, such as capecitabine plus trastuzumab with an OS of 24 months [30].

\section{Anti-Angiogenic Agents}

Angiogenesis is regarded as a key target in the development of next generation cancer therapy strategies, as the growth of vessels is needed for tumor growth and survival. Today, a combination of inhibition of the vascular endothelial growth factor (VEGF) ligand or the inhibition of VEGF by small molecules such as tyrosine kinase inhibitors are possible strategies. Substances such as bevacizumab are available, and side effects of these agents seem to be tolerable [1, 23, 28, 37]. New data show efficacy for multi-targeting small molecules inhibiting tyrosine kinases and VEGF or mTOR inhibitors but up to now with elevated toxicity. Therefore, further investigation of these pathways and substance groups is needs with respect to efficacy and toxicity effects.

\section{Other Treatment Options}

Bisphosphonates are indicated in all patients with bone metastasis [38-40], and newer substances such as denosumab are under investigation. In patients at risk of fracture or spinal compression, (neuro-) surgical intervention followed by radiation therapy for stabilization is needed [41]. In brain metastases, neurosurgical interventions and an interdisciplinary approach with surgeons, radiologists, and oncologists [42] is mandatory. Generally, the effects of surgery on tumor growth are not well enough defined [43] but promising. For burden relief, pleurodesis or ascites puncture [44] are options to relief symptoms. Adequate pain management is an essential basic part of medical treatment. Therapeutic options have become complex with large numbers of agents and mechanisms and other modalities such as surgical, pain management, or palliative procedures. New predictive factors of response and maximum benefit of a drug, with a minimum of side effects, must be the target.

Better defined translational research programs in $\mathrm{MBC}$ are needed to determine response potentials. The development of new inputs such as genomics and proteomics, or gene sequencing will improve our ability to better tailor individual treatment while respecting patient decisions and introduce better palliative care possibilities to prolong survival in a good quality of life setting. In the treatment of MBC, breast specialists and oncologists should focus on centralizing experience, improving standard of care, and providing palliative care with therapy management based on risk evaluation, predictive factors, toxicity risk, and the preference of the patients and perhaps their families. Factors such as performance status, cancer history, fatigue, dyspnea, reduced oral intake, use of strong analgesics, brain metastases, leukocytosis, and elevation of lactate dehydrogenase (LDH), creatinine, bilirubin, depression, and anxiety should be taken into account more [45] as these factors have an impact on survival and can be used in prognostic scores [46, 47] with good prediction of 3-week survival and in care planning and communication.

The European Association of Palliative Care has defined the following 6 evidence-based clinical recommendations for prognostic factors in advanced cancer patients. Using and communicating prognostic information is one of the core clinical skills and should be part of a multidisciplinary palliative care approach [48, 49]: i) In advanced cancer patient management, physicians should base their decisions about therapeutic interventions and settings of care considering both quality of life and life expectancy. An accurate prognostication of life expectancy will facilitate decision making both for professional carers and for patients with their families; ii) The clinical prediction of survival is a valid tool to obtain a general prognostic evaluation of patients, but is subject to a series of 
factors that limits its accuracy; its use is recommended with other prognostic factors; iii) Clinicians can use a number of clinical signs and symptoms that have proven to be associated with life expectancy in this patient population: performance status, cancer anorexia-cachexia syndrome signs and symptoms, dyspnea and cognitive failure or delirium; iv) Clinicians can use some laboratory variables associated with life expectancy: leukocytosis, lymphocytopenia, and high C-reactive protein. The need for a blood sample should be balanced with the clinical advantage that is envisaged and never taken lightly; v) Clinicians can make use of some easily applicable prognostic scores to make a rapid prediction capable of identifying classes of patients with significantly different life expectancies. At the moment, the Palliative Prognostic Score is the more readily available system including most of the factors; vi) Establishing a prognosis is part of the therapeutic alliance, patients have the right to be informed or not to be informed about their prognosis. Using and communicating prognostic information should be within the context of a comprehensive, individualized, patient-centered approach.

\section{Considerations for Terminally III Patients}

At this point, we would like to summarize the question 'How long does it make sense?' as follows: It makes sense to treat as long as any of the chosen therapeutic modalities will achieve tumor reduction and prolong remaining life time while maintaining a low rate of toxicity. However, especially in the light of this 'Breast Care Issue', there is a second implication to this question. It is still a fact that many patients with metastatic disease will be offered anticancer therapy until the end of life, and it may still happen that patients will receive chemotherapy until the end of their days despite it having been obvious early on, from a clinical point of view, that anticancer therapies cannot influence the course of disease and that the side effects of chemotherapy, surgery, or radiation outweigh the benefits. The imbalance between the realistic estimation of the 'point of no return' and the helpful use of anticancer therapeutics can be influenced by a wrong clinical assessment of disease progression and survival prediction. Gripp et al. [45] have shown that the survival of patients for more than 1 month is overestimated by physicians as well as the tumor board team in more than $70 \%$ of patients. Physicians constantly overestimate survival for patients with cancer. It has been shown that the question 'Would I be surprised if this patient died in the next year?' improves the end-of-life care by identifying patients with poor prognosis and is simple, feasible, and an effective tool for identifying patients with an increased risk of 1-year mortality [50]. At the same time, in $25 \%$ of cases, the clinical prediction of survival of the next 7 days was correct $[51,52]$. This means, that clinicians caring for patients with terminal cancer need to be aware of the ten- dency to overestimate survival as this is affecting patients prospects for achieving a good death. Wrong patient expectations maybe influenced by overoptimistic physicians. Interestingly, most patients want a qualitative prognosis, and only half of them want a quantitative time prognosis [53]. It is of key importance to find out what the individual patient wants to know [54]. In terms of the expectations of family members, the majority of men prefer an immediate disclosure of their wife being at an incurable stage of $\mathrm{MBC}$, but only $41 \%$ of these husbands received this information during the last week of the patients life or not at all [55]. Clinicians must try harder to integrate the family in treatment decisions.

In rare cases, administration may take the unusual attitude that dealing with terminally ill patients could convey a bad image. Not surprisingly, there is only little information that has dealt with the question when to stop anticancer treatment in this context. All multidisciplinary team members treating patients with advanced breast cancer must bear in mind that stopping anticancer treatment does not mean to stop all treatment but to focus instead on the patients' needs adapted to the reality of progression and end of life [56]. Knowing when it is time to shift from life-prolonging to more palliative approaches based on quality of life and comfort is emotionally and clinically challenging for patients, families, and physicians [57]. So questions remain regarding communication and communication skills, or what information should be given and how. Physicians - ideally having built a long-term relationship with the patient - can best help the patients decide which treatments are appropriate by taking time to explain all curative and palliative care options, if needed repeatedly, providing honest and timely prognostic information, making clear recommendations where desired, and facilitating patient-family discussion while respecting the familial and cultural background and affirming patients' choices as well as encouraging hope and a sense of control.

\section{Conclusion}

As long as there is agreement from the patient's side and experience in an interdisciplinary setting including early integration of palliative medicine, systemic treatment in MBC can be continued. Physicians' skills to estimate remaining lifetime in terminally ill patients must be improved to enhance shared decision-making. In the situation of terminal illness, palliative medicine in terms of best palliative care is the issue. Studies are urgently needed in the field of treatment and communication with terminally ill breast cancer patients.

\section{Disclosure Statement}

The authors declare no conflict of interest relating to the manuscript. 


\section{References}

1 Colozza M, Azambuja E, Personeni N, Lebrun F, Piccart M, Cardoso F: Achievements in systemic therapies in the pregenomic era in metastatic breast cancer. Oncologist 2007;12:253-70.

2 Wilcken N, Dear R: Chemotherapy in metastatic breast cancer: a summary of all randomized trials reported 2000-2007. Eur J Cancer 2008:44:2218-25.

3 Gennari A, Conte P, Rosso R, Orlandini C, Bruzzi $\mathrm{P}$ : Survival of metastatic breast carcinoma patient over a 20-year period; a retrospective analysis based on individual patient data from six consecutive studies. Cancer 2005;104:1742-50.

4 Chia SK, Speers CH, Dyachkova Y: The impact of new chemotherapeutic and hormone agents on survival in a population-based cohort of woman with metastatic breast cancer. Cancer 2007;110:973-9.

5 Saad ED, Katz A, Buyse M: Overall survival and post-progression survival in advanced breast cancer: a review of recent randomized clinical trials. J Clin Oncol 2010;28:1958-62.

6 Gueth U, Huang DJ, Schoetzau A, Holzgreve W, Wight E: Systemic treatment of metastatic breast cancer: the truth beyond the clinical trials. Oncology 2009;76:247-53.

7 Estevez LG, Tusquets I, Munoz M, Adrover E, Rovira PS, Segui MA, Rodriguez CA, Lescure AR, Ruiz M, Alvarez I, Mata JG: Advanced breast cancer: chemotherapy phase III trials that change a standard. Anti-Cancer Drugs 2007;18:843-59.

8 Moreno-Aspitia A, Perez EA: Anthracycline- and/ or taxane-resistant breast cancer: results of a literature review to determine the clinical challenges and current treatment trends. Clinical Therapeutics 2009;31:1619-40.

9 Therasse P, Arbuck SG, Eisenhauer EA: New guidelines to evaluate the response to treatment in solid tumors. European Organization for Resarch and Treatment of Cancer, National Cancer Institute of the United States, National Cancer Institute of Canada. J Nati Cancer Inst 2000;92:205-16.

10 Rapiti E, Verkooijen HM, Vlastos G, Fioretta G, Neyroud-Caspar I, Sappino AP, Chappuis PO, Bouchardy C: Complete excision of primary breast tumor improves survival of patients with metastatic breast cancer at diagnosis. JCO 2006;24:2743-9.

11 Von Minckwitz G, du Bois A, Schmidt M, Maass N, Cufer T, de Jongh FE, Maartense E, Zielinski C, Kaufmann M, Bauer W, Baumann $\mathrm{KH}$, Clemens MR, Duerr R, Uleer C, Andersson M, Sein RC, Nekljudova V, Loibl S: Trastuzumab beyond progression in human epidermal growth factor receptor 2-positive breast cancer: a german breast group 26/breast international group 03-05 study. J Clin Oncol 2009;27:1999-2006.

12 Huyge V, Garcia C, Alexiou J, Ameye L, Vanderlinden B, Lemort M, Bergmann P, Awada A, Dody JJ, Flamen P: Heterogeneity of metabolic response to systemic therapy in metastatic breast cancer patients. Clin Oncol (R Coll Radiol) 2010;22:818-27.

13 Temel JS, Greer JA, Muzikansky A, Gallagher ER, Adame S, Jackson VA, Dahlin CM, Blinderman CD, Jacobsen J, Pirl WF, Billings JA, Lynch TJ: Early palliative care for patients with metastatic nonsmall-cell lung cancer. N Eng J Med 2010;363:73342.

14 Matsuyama R, Reddy S, Smith TJ: Why do patients choose chemotherapy near the end of life? A review of the perspective of those facing death from cancer; J Clin Oncol 2006;24:3331-2.
15 De Haes H, Koedoot N: Patient centered decision making in palliative cancer treatment: a world of paradoxes; Patient Educ Couns 2003;50:43-9.

16 Gattellari M: Shared decisions in cancer care. Soc Sci Med 2001;52:1865-78.

17 Kiesler DJ, Auerbach M: Optimal matches of patient preferences for information, decisionmaking and interpersonal behavior: evidence, models and interventions. Patient Educ Couns 2006;61:319-41.

18 Baile WF, Buckman R, Lenzi R, Glober G, Beale EA, Kudelka AP: SPIKES - a six step protocol for delivering bad news: application to the patient with cancer. Oncologist 2000;5:302-11.

19 Gunten CF, Ferris FD, Emmanuel LL: Ensuring competency in end-of-life care. Communication and relational skills. JAMA 2000;284:3051-7.

20 Amir E, Clemons M, Freedman OC: Tissue confirmation of disease recurrence in patients with breast cancer; pooled analysis of two large prospective studies. J Clin Oncol 2010;28(15 suppl): (abstr 1007).

21 Guarneri V, Giovannelli S, Ficarra G, Bettelli S, Maiorana A, Piacentini F, Barbieri E, Dieci MV, D'Amico R, Jovic G, Conte P: Comparison of HER-2 and hormone receptor expression in primary breast cancers and asynchronous paired metastases: impact on patient management. Oncologist 2008:13:838-44.

22 Sari E, Guler G, Hayran M, Gullu I, Altundag K, Ozisik Y: Comparative study of immunohistochemical detection of hormone receptor status and HER-2 expression in primary and paired recurrent/ metastatic lesions of patients with breast cancer. Med Oncol 2010; DOI 10.1007/s12032-010-9418-2; Epub ahead of print.

23 Miles DW: Recent advances in systemic treatment: when HER2 is not the target: advances in the treatment of HER2-negative metastatic breast cancer. Breast Cancer Res 2009;11:208.

24 Gibson LJ, Dawson CK, Lawrence DH, Bliss JM: Aromatase inhibitors for treatment of advanced breast cancer in postmenopausal women. Cochrane Database Syst Rev 2007;(4):CD003370.

25 Vergote J, Amant F, Leunen K: Metastatic breast cancer: sequencing hormonal therapy and positioning of fulvestrant. Int J Gynecol Cancer 2006;16(suppl 2):524-6.

26 Kaufmann B, Mackey JR, Clemens MR: Trastuzumab plus anastrozole versus anastrozole alone for the treatment of postmenopausal women with human epidermal growth factor receptor 2-positive, hormone receptor-positive metastatic breast cancer. Results from the randomized phase III TAnDEM study. J Clin Oncol 2009;27:5529-37.

27 Johnston S, Pippen J Jr, Pivot Y: Lapatinib combined with letrozole versus letrozole and placebo as first-line therapy for postmenopausal hormone receptor-positive metastatic breast cancer. J Clin Oncol 2009;27:5538-46.

28 Morrow PKH, Zambrana F, Esteva FJ: Recent advances in systemic therapy: advances in systemic therapy for HER2-positive metastatic breast cancer. Breast Cancer Res 2009;11:2007.

29 Slamon DJ, Leyland-Jones B, Shak S: Use of chemotherapy plus a monoclonal antibody against HER2 for metastatic breast cancer that overexpresses Her2. N Eng J Med 2001;344:783-92.
30 Bartsch R, Wenzel C, Altorjai G, Pluschnig U, Rudas M, Mader RM, Gnant M, Zeilinski CC, Steger GG: Capecitabine and trastuzumab in heavily pretreated metastatic breast cancer. J Clin Oncol 2007;25:3853-8.

31 Cameron D, Casey M, Press M, Lindquist D Pienkowski T, Romieu CG, Chan S, JagielloGruszfeld A, Kaufmann B, Crown J, Chan A, Campone M, Viens P, Davidson N, Gorbounova V, Raats JI, Skarlos D, Newstat B, Roychowdhury D, Paoletti P, Oliva C, Rubin S, Stein S, Geyer CE: A phase III randomized comparison of lapatinib plus capecitabine versus capecitabine alone in women with advanced breast cancer that has progressed on trastuzumab: updated efficacy and biomarker analyses. Breast Cancer Res Treat 2008;112:533-43.

32 Blackwell KL, Burstein H, Storniolo AM, Rugo H, Sledge G, , Koehler M, Ellis C, Casey M, Vulkelja S, Bischoff J, Baselga J, O'Shaugnnessy: Randomized study of lapatinib alone or in combination with trastuzumab in women with erb B-2 positive, trastuzumab-refractory metastatic breast cancer. JCO 2010;28:1124-30.

33 Jones D, Ghersi D, Wilcken N: Addition of drugs to a chemotherapy regimen for metastatic breast cancer. Cochrane Database Syst Rev 2006;(3): CD003368.

34 Cardoso F: Combination versus sequential single-agent chemotherapy. J Natl Cancer Inst 2009;101:1171-81.

35 Piccart-Gebhart MJ, Burzykowski T, Buyse M, Sledge G, Carmichael J, Lück HJ, Mackey JR, Nabholtz JM, Paridaens R, Biganzoli L, Jassem J, Bontenbal M, Bonneterre J, Chan S, Basaran GA, Therasse P: Taxanes alone or in combination with anthracyclines as a first-line therapy in patients with metastatic breast cancer. J Clin Oncol 26:1980-6.

36 Mauri D, Kamposioras K, Tsali L, Bristianou M, Valachis A, Karathanasi I, Georgiou C, Polyzos NP: Overall survival benefit for weekly vs. threeweekly taxanes regimens in advanced breast cancer: a meta-analysis; Cancer Treat Rev 2010;36:6974.

37 Miller K, Wang M, Gralow J: Paclitaxel plus bevacizumab versus paclitacel alone for metastatic breast cancer. N Engl J Med 2007;357:266-76.

38 Diel LJ, Body JJ, Lichinister MR: Improved quality of life after long-term treatment with the bisphosphonate ibandronate in patients with metastatic bone disease due to breast cancer. Eur J Cancer 2004;40:1704-12.

$39 \mathrm{Ha} \mathrm{TV}, \mathrm{Li} \mathrm{H}$ : Meta-analysis of clodronate and breast cancer survival. Br J Cancer 2007;96:1796801.

40 Lipton A, Steger GG, Figueroa J: Randomized active-controlled phase II study of denosumab efficacy and safety in patients with breast cancerrelated bone metastases. J Clin Oncol 2007;25: 4431-7.

41 Patchell RA, Tibbs PA, Regine WF, et al.: Direct decompressive surgical resection in the treatment of spinal cord compression caused by metastatic cancer; a randomized trial. Lancet 2005;366:643-8.

42 Chinot OL: Cerebral metastases. Rev Prat 2006; 56:1799-804.

43 Demicheli R, Retsky MW, Hrushesky WJ, Baum M, Gukas ID: The effects of surgery on tumor growth: a century of investigations. Ann Oncol 2008;19:1. 
44 Shaw P, Agarwal R: Pleurodesis for malignant pleural effusions. Cochrane Database Syst Rev 2004;(1):CD002916.

45 Gripp S, Moeller S, Bölke E, Schmitt G, Matuschek C, Asgari S, Asgharzadeh F, Roth S, Budach W, Franz M, Willers R: Survival prediction in terminally ill cancer patients by clinical estimates, laboratory tests, and self-rated anxiety and depression; J Clin Oncol 2007;25:3313-20.

46 Sang-Yeon S, Young Seon C, Jae Young S, Young Sung K, Chang Hwan Y, Daeyoung K, Shin P, Sooa K, Ji Yeon S, Su Huyn K: Construction of a new, objective prognostic score for terminally ill cancer patients: a multicenter study. Support Care Cancer 2010;18:151-7.

47 Lau F, Downing M, Lesperance M, Shaw J, Kuziemsky C: Use of palliative performance scale in end-of-life prognostication. J Palliat Med 2006;9:1066-75.

48 Maltoni M, Caraceni A, Brunelli C, Broeckaert B, Christakis N, Eychmueller S, Glare P, Nabal M, Vigano A, Larkin P, De Conno F, Hanks G, Kaasa S: Prognostic factors in advanced cancer patients: evidence-based clinical recommendations - a study by the steering committee of the European association for palliative care. J Clin Oncol 2005;23:6240-8.

49 Glare PA, Sinclair CT: Palliative medicine review: prognostication. J Palliat Med 2008;11:84-103.

50 Moss AH, Lunney JR, Culp S, Auber M, Kurlan S, Rogers J, Dower J, Abraham J: Prognostic significance of the 'surprise' question in cancer patients. J Palliat Med 2010;13:837-40.

51 Glare P, Virik K, Jones M, Hudson M, Eychmuller S, Simes J, Christakis N: A systematic review of physicians survival predictions in terminally ill cancer patients. MBJ 2003;327:1048-9.

52 Gordon EJ, Daugherty CK: Hitting you over the head: oncologists disclosure of prognosis to advanced cancer patients. Bioethics 2003;17:142-68.

53 Kaplowitz SA, Such JR, Safron DSC: Physician communication with seriously ill cancer patients: results of a survey of physicians; in De Vries B (ed): End of Life Issues: Interdisciplinary and Multidimensional Perspectives. New York, NY, Springer Publishing Company, 1999, pp. 205-277.

54 Butow PN, Dowsett S, Hagerty R, Tattersall MH: Communicating prognosis to patients with metastatic disease: what do they really want to know? Support Care Cancer 2002:10:161-8.

55 Dahlstrand H, Hauksdottir A, Valdimarsdottir U, Fürst CJ, Bergmark K, Steineck G: Disclosure of incurable illness to spouses: do they want to know? A Swedish population-based follow-up study; J Clin Oncol 2008;26:4229.

56 Weissman DE: Decision making at a time of crisis near the end of life. JAMA 2004;292:1738-43. Comment in: JAMA 2005;293:162.

57 Begles A, Blackwood B: Truth-telling versus hope: a dilemma in practice. Int J Nurs Pract 2000;6:26-31. 